\title{
Micellar High Performance Liquid Chromatographic Determination of a Binary Mixture of Rivaroxaban and Clopidogrel and Application to Biological Fluids
}

\section{Heba Abd El-Aziz*, Ibrahim F, Sharaf El-Din M and Fathy ME}

Pharmaceutical Analytical Chemistry Department, Faculty of Pharmacy, Mansoura University, Mansoura, Egypt

"Corresponding author: Heba Abd El-Aziz, Pharmaceutical Analytical Chemistry Department, Faculty of Pharmacy, Mansoura University Mansoura, 35516, Egypt, Tel: +20-50-2247496; E-mail: dr_heba_abdelaziz@hotmail.com

Received date: August 02, 2016; Accepted date: September 22, 2016; Published date: September 25, 2016

Copyright: () 2016 Heba Abd El-Aziz. This is an open-access article distributed under the terms of the Creative Commons Attribution License, which permits unrestricted use, distribution, and reproduction in any medium, provided the original author and source are credited.

\begin{abstract}
A selective and short time consuming cost effective micellar high performance liquid chromatographic technique is created for the separation and simultaneous assay of two antiplatelet drugs, Rivaroxaban (RIV) with Clopidogrel (CLP). The developed and validated method is characterized by its simplicity, sensitivity and rapidness. Chromatographic study is performed on a $3 \mathrm{~mm} \times 4.6 \mathrm{~mm}$ i.d., $2 \mu \mathrm{m}$ pore size highly porous monolithic (chromolith ${ }^{\circledR}$ reversed phase) column to obtain good chromatographic separation using a mixture of $0.185 \mathrm{M}$ sodium dodecyl sulphate (SDS), $8 \% \mathrm{n}$-propanol, $0.3 \%$ triethylamine (TEA) as a mobile phase, adjusted at $\mathrm{pH} 4.0$ using $0.02 \mathrm{M}$ orthophosphoric acid and pumped at a flow rate of $1 \mathrm{~mL} / \mathrm{min}$. using UV detector at $235 \mathrm{~nm}$. The internal standard (IS) of choice was Raloxifen (RAL) and separation was performed at room temperature. Good linearity for the proposed method was obtained over the ranges of $0.3-9.0 \mu \mathrm{g} / \mathrm{mL}$ and $0.5-25.0 \mu \mathrm{g} / \mathrm{mL}$ with limits of detection (LOD) of $0.05,0.16 \mu \mathrm{g} / \mathrm{mL}$ and limits of quantitation (LOQ) of $0.16,0.49 \mu \mathrm{g} / \mathrm{mL}$ for rivaroxaban and clopidogrel, respectively and retention time was 1.9 and $5 \mathrm{~min}$., respectively. Simultaneous analysis of the studied drugs in their laboratory prepared mixture and tablet was done as an application for the proposed method showing satisfactory results. Also biological fluids were assayed using the proposed method for the determination of rivaroxaban in human plasma and for both drugs in human urine with no need for previous extraction. The data obtained by the proposed method was statistically evaluated and compared with the reference one showing good accuracy and precision of the proposed method.
\end{abstract}

Keywords: Micellar chromatographic technique; Simultaneous assay; Rivaroxaban and clopidogrel; Laboratory prepared tablet; Human plasma and urine

\section{Introduction}

Rivaroxaban (RIV) (Figure 1a); (S)-5-chloro-N-\{[2-oxo-3-[4-(3oxomorpholin-4-yl) phenyl] oxazolidin-5-yl] methyl\} thiophene-2carboxamide [1], it is considered one of the available orally active anticoagulants, according to mechanism of action it is direct factor Xa inhibitor. FDA approved rivaroxaban to avoid occurrence of deep vein thrombosis which may lead to pulmonary embolism in adults with hip and knee replacement surgery [2]. Clopidogrel (CLP) (Figure 1b);((+)(S)-methyl2-(2-chlorophenyl)-2-(6,7-dihydrothieno[3,2-

c]pyridin-5(4H)yl)acetate (1), it is an oral antiplatelet agent belongs to thienopyridine class and acts by inhibiting adenosine diphosphate mediated platelet aggregation [2]. Both drugs are used to prevent blood clots in coronary artery disease, peripheral and cerebro vascular disease and to avoid myocardial infarction (2). RIV is not official in any pharmacopoeia. From literature survey several HPLC methods have been published for the determination of RIV either alone or in presence of other drugs. The reported HPLC methods for RIV alone [3-12], HPLC combined with other techniques such as TLC and LC/MS [13], TLC and First derivative spectrophotometry [14], HPLCtandem mass spectrometry $[15,16]$. Few HPLC methods were reported for determination of RIV with other drugs $[16,17]$. CLP is official in the United State Pharmacopoeia (USP) (3). Literature survey revealed that many HPLC methods have been published for its determination either alone [18-21] or in combination with other drugs [22-26].<smiles>COC(=O)[C@@H](c1ccccc1Cl)N1CCc2sccc2C1</smiles>

Figure 1: The studied drugs chemical structures.

Assay of synthetic mixture of RIV and CLP has been described previously using HPLC method with UV detection at $240 \mathrm{~nm}$ [17], but it could not be used for determination of rivaroxaban in plasma. The developed micellar HPLC method has the advantage over the previously reported HPLC one [27] on that the low cost and low toxicity of the mobile phase (green chemistry) due to low percentage of organic solvent used (only $8 \% \mathrm{n}$-propanol). Also, solubilizing ability of 
Citation: Heba Abd El-Aziz, Ibrahim F, Sharaf El-Din M and Fathy ME (2016) Micellar High Performance Liquid Chromatographic Determination of a Binary Mixture of Rivaroxaban and Clopidogrel and Application to Biological Fluids. Pharm Anal Acta 7: 506. doi: $10.4172 / 2153-2435.1000506$

Page 2 of 11

micelles permits the direct injection of biological fluids eluting protein in the solvent front. So, RIV in human plasma and both drugs in human urine could be determined.

Nothing has been reported for micellar determination of both drugs. So, a new cost effective micellar high performance liquid chromatographic technique is developed for the simultaneous determination of a binary mixture of the studied drugs, for RIV in human plasma and for both drugs in urine.

Rivaroxaban and clopidogrel are prepared in recommended ratio of 1:5. Both drugs can be separated and quantitated using the proposed micellar HPLC technique showing high accuracy and precision.

In our proposed micellar HPLC technique, simultaneous analysis of RIV and CLP binary mixture was done using UV detector showing good resolution with assay time no more than $5 \mathrm{~min}$. The studied drugs can be quantitated in human plasma and urine using the proposed method with satisfactory results. Validation for the proposed method was done as per International Conference on Harmonization $(\mathrm{ICH})$ guidelines [28].

\section{Materials and Methods}

\section{The used materials and conditions study}

Devices used: A Merck Hitachi Chromatograph model L-7100 with a Rheodyne injector valve its loop capacity $20 \mu \mathrm{L}$ attached with a Merck Hitachi L-7400 UV detector and adjusted at $235 \mathrm{~nm}$ was used for our Chromatographic technique. The resulting peaks were drawn on a Merck Hitachi D-7500 integrator. Millipores filter Sibata was used for the mobile phase filtration and Merck solvent L-7612 degasser was used for its degassing. $\mathrm{pH}$ measurements were done using a Consort P-901 pH-meter. Ultrasonic bath, model SS 101 H 230, USA was used for sonication of all prepared solutions.

Chemicals and Materials: High analytical grade Reagents were used for our work especially the solvents were of HPLC grade. Rivaroxaban and Clopidogrel were provided by Memphis Co. for pharm. \& Eva Pharma Company, Cairo, Egypt, respectively.

Alexandria CO. for Pharmaceuticals, Alexandria, Egypt was the source for Raloxifen internal standard (IS). Laboratory prepared tablet consists of $15 \mathrm{mg}$ RIV, $75 \mathrm{mg}$ CLP, $20 \mathrm{mg}$ talc powder, $15 \mathrm{mg}$ maize starch, $15 \mathrm{mg}$ lactose and $7 \mathrm{mg}$ magnesium stearate.

Riedel-deHäen (Sleeze, Germany) was the source for Sodium dodecyl sulphate (SDS) $90 \%$, triethylamine (TEA) and orthophosphoric acid $85 \%$ which used for mobile phase preparation.

Methanol, n-propanol and acetonitrile were obtained from SigmaAldrich (Germany) as HPLC grade. Human plasma was kindly provided by Mansoura University Hospitals, Mansoura, Egypt and kept frozen $\left(-5^{\circ} \mathrm{C}\right)$ until used and urine sample was taken from a healthy person.

Chromatographic Conditions: Column: a monolithic $3 \mathrm{~mm} \times 4.6$ $\mathrm{mm}$ i.d., $2 \mu \mathrm{m}$ pore size highly porous (chromolith ${ }^{\circ}$ reversed phase) column, Shimadzu, Japan.

Mobile phase solution consisting of $0.185 \mathrm{M}$ SDS, $8 \%$ n-propanol, $0.3 \%$ TEA, adjusted at $\mathrm{pH} 4.0$ using $0.02 \mathrm{M}$ orthophosphoric acid. 1 $\mathrm{mL} / \mathrm{min}$ was the flow rate of choice.

Room temperature was selected for operation of the column and we adjusted the wavelength at $235 \mathrm{~nm}$. The internal standard of choice was
Raloxifen since it gave well separated and resolved peaks from RIV and CLP peaks.

Standard Solutions: Stock solutions of $200 \mu \mathrm{g} / \mathrm{mL}$ rivaroxaban, clopidogrel and raloxifen (IS) were prepared by dissolving $20 \mathrm{mg}$ of RIV, CLP or RAL separately in methanol in $100 \mathrm{~mL}$ volumetric flask using ultrasonic bath to aid the solubilization. Working standard solutions were prepared from the stock solutions by suitable dilution using methanol. Laboratory prepared mixture solutions of both drugs were prepared by mixing appropriate volumes of rivaroxaban and clopidogrel stock solutions into $100 \mathrm{~mL}$ volumetric flasks using methanol as diluting solvent to reach the pharmaceutical ratio of 1:5 for RIV and CLP, respectively. Storage of drug solutions in the refrigerator keeps them stable for at least 3 weeks without alteration.

\section{Assay}

Calibration graphs establishment: A series of $10 \mathrm{~mL}$ volumetric flasks was used. Transfer accurately measured volumes of the drug working standard solutions to reach final concentration in the range of $0.3-9.0 \mu \mathrm{g} / \mathrm{mL}$ for RIV and $0.5-25.0 \mu \mathrm{g} / \mathrm{mL}$ for CLP. $0.25 \mathrm{~mL}$ of RAL standard solution (internal standard) was added to each flask to obtain a final concentration of $5 \mu \mathrm{g} / \mathrm{mL}$. Then, the mobile phase was used to complete these solutions to the mark and mixed well. Under the optimum chromatographic conditions, $20 \mu \mathrm{L}$ were injected (triplicate) and eluted with the mobile phase. The plots of average peak area ratios (Drug/I.S.) versus the final concentrations of the drugs in $\mu \mathrm{g} / \mathrm{mL}$ were constructed. Alternatively, the corresponding regression equations were derived.

RIV/CLP binary mixtures assay: A series of $10 \mathrm{~mL}$ volumetric flasks were used to transfer volumes of RIV and CLP standard solutions in their pharmaceutical ratio. The solutions were diluted to the mark with the mobile phase and mixed well. Volumes of $20 \mu \mathrm{L}$ were injected (triplicate) and eluted with the mobile phase under the optimum chromatographic conditions. The average peak area ratios (Drug/I.S.) versus the final concentrations of the drugs in $\mu \mathrm{g} / \mathrm{mL}$ were plotted. Alternatively, the corresponding regression equations were derived. The percentages found were calculated from the calibration graphs or the corresponding regression equations.

Analysis of the studied drugs in their laboratory prepared tablets: Ten laboratory prepared tablets were mixed well, then amount equivalent to $15 \mathrm{mg}$ RIV and $75 \mathrm{mg}$ CLP were accurately weighed and transferred into $100 \mathrm{~mL}$ volumetric flask and about $80 \mathrm{~mL}$ of methanol were added. Sonication of the flask contents for $30 \mathrm{~min}$ was applied, and then the flask was completed to the mark with the same solvent and filtered. Aliquots of the filtrate containing suitable concentrations of both studied drugs over the working concentration ranges were analyzed as illustrated under "construction of calibration graphs". The nominal contents of the drugs in tablet were calculated either from previously plotted calibration curves or using the corresponding regression equations.

RIV analysis in spiked human plasma: From RIV working standard solution we transferred volumes into a set of $10 \mathrm{~mL}$ volumetric flasks to obtain a final concentration in the range of $0.3-0.65 \mu \mathrm{g} / \mathrm{mL}$ and diluted by adding $7 \mathrm{~mL}$ of the mobile phase. $1 \mathrm{~mL}$ of the plasma was added to each flask, and then we complete the flasks with the mobile phase to the mark and mixed well. Under the previously mentioned chromatographic conditions, $20 \mu \mathrm{L}$ was injected (triplicate) from each concentration using the mobile phase as the eluent. We carried out blank experiment simultaneously (using $1 \mathrm{~mL}$ human plasma in 
Citation: Heba Abd El-Aziz, Ibrahim F, Sharaf El-Din M and Fathy ME (2016) Micellar High Performance Liquid Chromatographic Determination of a Binary Mixture of Rivaroxaban and Clopidogrel and Application to Biological Fluids. Pharm Anal Acta 7: 506. doi: $10.4172 / 2153-2435.1000506$

mobile phase). The obtained peak area was plotted against the concentration of RIV in $\mu \mathrm{g} / \mathrm{mL}$.

RIV and CLP assay in spiked human urine: We transferred volumes of RIV and CLP working standard solutions into a series of $10 \mathrm{~mL}$ volumetric flasks, so that final concentrations are in the range of $0.3-1.5 \mu \mathrm{g} / \mathrm{mL}$ and $0.6-2.5 \mu \mathrm{g} / \mathrm{mL}$ for RIV and CLP respectively. The contents of the flask were diluted with $7 \mathrm{~mL}$ of the mobile phase. To each flask $1 \mathrm{~mL}$ of human urine was added, and then the flasks were completed with the mobile phase to the mark and mixed well. Under the previously mentioned chromatographic conditions, $20 \mu \mathrm{L}$ was injected (triplicate) from each concentration using the mobile phase as the eluent. A blank experiment was performed simultaneously (using 1 $\mathrm{mL}$ human urine in mobile phase). The peak area was plotted against each drug concentration in $\mu \mathrm{g} / \mathrm{mL}$.

\section{Results and Discussions}

A rapid, reliable and highly selective miceller HPLC technique was designed and undergone validation for the simultaneous analysis of two antiplatelet drugs (RIV and CLP). Good separation was obtained using the proposed study with resolution (Rs) $=10.48$ and selectivity factor $(\alpha)=3.83$ in a short time not more than $5 \mathrm{~min}$. A typical chromatogram for a prepared mixture of both mentioned drugs was illustrated in Figure 2 under the mentioned chromatographic conditions. 1.9, 2.9 and $5 \mathrm{~min}$. are the retention times for RIV, RAL, and CLP, respectively. The proposed assay shows very high sensitivity as it was used for quantitation of $0.3 \mu \mathrm{g} / \mathrm{mL}$ of RIV and $0.5 \mu \mathrm{g} / \mathrm{mL}$ of CLP accurately. Assay of the studied drugs in human urine and RIV in human plasma was performed as an application of the proposed technique.

\section{Chromatographic performance optimization}

We can summarize our many trials to obtain well-defined sharp symmetrical and separated peaks as follows:

Choice of a suitable column: Shim-pack VP-ODS column $(250 \mathrm{~mm}$ $\times 4.6 \mathrm{~mm}$ i.d., $5 \mu \mathrm{m}$ particle size), Shimadzu, Kyoto, Japan; Symmetry C18 column $(250 \mathrm{~mm} \times 4.6 \mathrm{~mm}$ i.d., $5 \mu \mathrm{m}$ particle size $)$, and a monolithic highly porous chromolith reversed phase column $(3 \mathrm{~mm} \times$ $4.6 \mathrm{~mm}$ i.d., $2 \mu \mathrm{m}$ pore size), Shimadzu, Kyoto, Japan were used to evaluate chromatographic performance and to reach good separation results. During our experimental trials, the last column was found to be the most suitable one since the peaks obtained were symmetrical and sharp with high resolution. Unsymmetrical and broad tailed peaks within too long time were obtained using the first two columns.

Wavelength selection: For selection of the optimum detection wavelength, the studied drugs absorption spectra were scanned using UV spectrophotometer, it was found that maximum wave length for the RIV and CLP (223.8 and $249 \mathrm{~nm}$ ), respectively. The most suitable wave length for both drugs chromatographic assay in the mobile phase was found to be $235 \mathrm{~nm}$ at which the sensitivity of the method was very high and separation occurs with a good response (Figure 3 ).

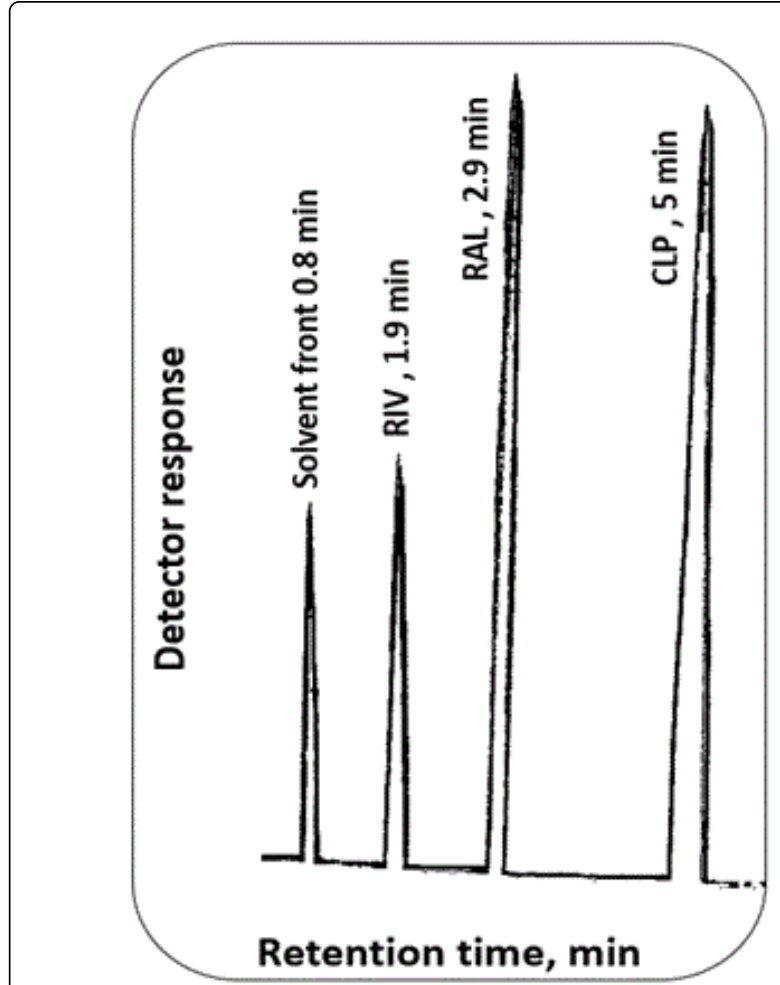

Figure 2: Synthetic mixture chromatogram of $2.0 \mu \mathrm{g} / \mathrm{mL}$ RIV and $10.0 \mu \mathrm{g} / \mathrm{mL}$ CLP using $5.0 \mu \mathrm{g} / \mathrm{mL}$ RAL (I.S) in a mobile phase of $0.185 \mathrm{M}$ SDS, $0.3 \%$ triethylamine, $8 \% \mathrm{n}$-propanol adjusted at $\mathrm{pH} 4.0$ using $0.02 \mathrm{M}$ orthophosphoric acid.

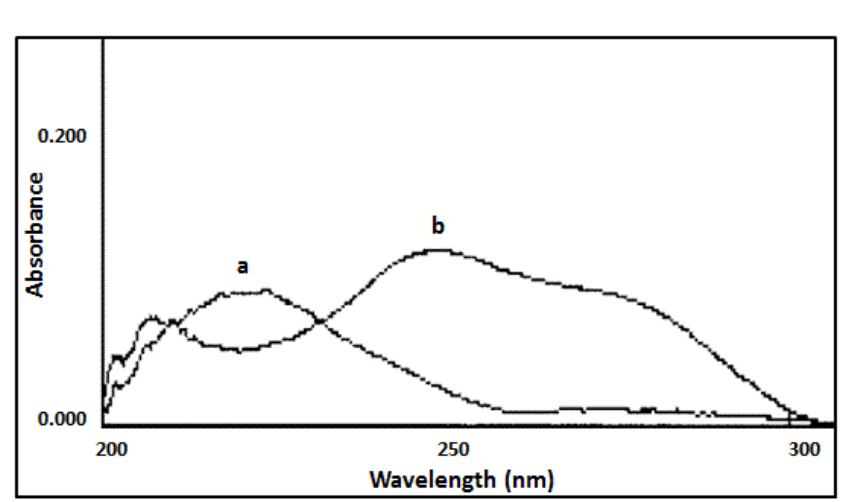

Figure 3: UV spectra of (a) RIV and (b) CLP $(2.0 \mu \mathrm{g} / \mathrm{mL})$ of each in methanol.

Mobile phase constituents: From the log P values of RIV (1.5) and CLP (3.8), we concluded that both drugs could be analyzed using a micellar conditions with SDS concentration less than $0.2 \mathrm{M}$. To improve efficiency of separation by the micellar media, short chain alcohol is necessary to be added (27). Hence, modifications in the mobile phase composition were used for improving the chromatographic system behavior such as: the type and \% concentration of the organic modifier, the SDS concentration, and the $\mathrm{pH}$. Table 1 shows the obtained results. 
Citation: Heba Abd El-Aziz, Ibrahim F, Sharaf El-Din M and Fathy ME (2016) Micellar High Performance Liquid Chromatographic Determination of a Binary Mixture of Rivaroxaban and Clopidogrel and Application to Biological Fluids. Pharm Anal Acta 7: 506. doi: $10.4172 / 2153-2435.1000506$

Page 4 of 11

\begin{tabular}{|c|c|c|c|c|c|}
\hline Parameter & & Number of theoretical plates (N) & & Resolution (R) & Selectivity factor $(\alpha)$ \\
\hline & & RIV & CLP & & \\
\hline \multirow[t]{5}{*}{$\%$ of organic modifier (v/v) } & 6 & 2333 & 8283 & 11.23 & 3.92 \\
\hline & 8 & 2231 & 4054 & 10.48 & 3.83 \\
\hline & 10 & 2110 & 3455 & 11.06 & 3.64 \\
\hline & 12 & 1539 & 1548 & 7.2 & 3.68 \\
\hline & 14 & 1000 & 3184 & 10 & 3.25 \\
\hline \multirow[t]{7}{*}{ Concentration of SDS, M } & 0.1 & 3353 & 4135 & 31 & 4.87 \\
\hline & 0.125 & 2880 & 7320 & 18 & 4.57 \\
\hline & 0.15 & 2369 & 7073 & 10.6 & 3.96 \\
\hline & 0.175 & 1897 & 3876 & 9.35 & 3.63 \\
\hline & 0.185 & 2214 & 3456 & 11.06 & 3.64 \\
\hline & 0.2 & 1689 & 3231 & 9 & 3.63 \\
\hline & 0.2 & 1736 & 1690 & 2.29 & 1.56 \\
\hline \multirow[t]{6}{*}{$\mathrm{pH}$ of the medium } & 2.8 & 2187 & 6542 & 12.8 & 3.34 \\
\hline & 3 & 2290 & 7448 & 13.9 & 3.8 \\
\hline & 3.5 & 2267 & 4895 & 15.5 & 4.18 \\
\hline & 4 & 2231 & 4054 & 10.48 & 3.83 \\
\hline & 4.5 & 2374 & 5485 & 14.6 & 4.25 \\
\hline & 5 & 1697 & 4312 & 10.19 & 3.9 \\
\hline Flow rate & 0.8 & 1307 & 2383 & 11.05 & 4.18 \\
\hline \multirow[t]{2}{*}{$(\mathrm{mL} / \mathrm{min})$} & 1 & 2232 & 4054 & 10.48 & 3.83 \\
\hline & 1.2 & 1098 & 1814 & 9.34 & 4.21 \\
\hline
\end{tabular}

Table 1: Experimental parameters and its influence on the number of theoretical plates, resolution and selectivity factor.

Organic modifier type: During the experimental study, different organic modifiers were tried in order to find the best one for good chromatographic separation of both drugs under assay. Methanol, acetonitrile and n-propanol were the organic modifiers under study. It was found that; using methanol and acetonitrile made the separation takes a longer time and the produced peaks were broad. Also, methanol and acetonitrile showed low sensitivity for RIV and very low sensitivity for CLP. Well resolved and highly sensitive peaks within a short time (not more than $5 \mathrm{~min}$.) were obtained using $\mathrm{n}$-propanol. So, $\mathrm{n}$-propanol is the organic modifier of choice.

(\%) of Organic modifier: We studied the influence of changing the $\%$ concentration of $\mathrm{n}$-propanol on the retention times and selectivity of the drugs under assay using mobile phases containing n-propanol in concentrations range from $6 \%$ to $14 \%$. We found that using concentration of $6 \%$ resulted in a decrease in sensitivity of both drugs and increase in their retention times. On using 12\%, a slight broadening of two peaks occurred. In case of $14 \%$ a sharp decrease in the sensitivity of both drugs. Using $8-10 \% \mathrm{n}$-propanol gave the same results, but with $8 \% \mathrm{n}$-propanol, symmetrical peaks were obtained. So, the optimum chromatographic performance was obtained upon using $8 \%$ n-propanol regarding resolution and number of theoretical plates of both drugs.

Molar concentration of SDS: We used mobile phases containing SDS concentration in the range $0.1-0.2 \mathrm{M}$ to study the effect of its concentration change on the retention times and selectivity of the both studied drugs. Upon decreasing the \% concentration of SDS, the retention times of both RIV and CLP increased and sensitivity decreased. From the study, we found that 0.185 M SDS was the optimum concentration to achieve good chromatographic performance regarding resolution and number of theoretical plates of both drugs. Great increase in the retention time and sharp decrease in sensitivity of both studied drugs upon using concentrations less than 0.1 M SDS. The solvent front greatly interfered with the peak of RIV with concentrations higher than $0.2 \mathrm{M}$ SDS.

Value of $\mathrm{pH}$ : The influence of $\mathrm{pH}$ changing of the mobile phase on the selectivity and retention times of both studied drugs using $\mathrm{pH}$ ranging from 2.8 to 5 resulted in: On increasing the $\mathrm{pH}$ above 4.5 , the sensitivity of RIV and CLP greatly decreased and the retention time of 
Citation: Heba Abd El-Aziz, Ibrahim F, Sharaf El-Din M and Fathy ME (2016) Micellar High Performance Liquid Chromatographic Determination of a Binary Mixture of Rivaroxaban and Clopidogrel and Application to Biological Fluids. Pharm Anal Acta 7: 506. doi: $10.4172 / 2153-2435.1000506$

Page 5 of 11

CLP increased. At $\mathrm{pH}$ less than 3, great decrease in the sensitivity of CLP is obtained. So, $\mathrm{pH} 4.0$ was the most appropriate one giving well resolved peaks and high sensitivity with a high number of theoretical plates (illustrated in Table 1).

Influence of flow rate change: The effect of changing flow rate over the range of $0.8-1.2 \mathrm{~mL} / \mathrm{min}$ on peaks separation of both studied drugs was studied. At a flow rate of $0.8 \mathrm{~mL} / \mathrm{min}$, broad peaks were obtained with an increase in retention time, while at a flow rate $1.2 \mathrm{~mL} / \mathrm{min}$, the resolution of the two drugs and the internal standard is affected. Table 1 illustrates that $1 \mathrm{~mL} / \mathrm{min}$. was the optimal flow rate producing the highest number of theoretical plate and good separation in a short assay time ( $5 \mathrm{~min})$.

The internal standard nature: A $(5 \mu \mathrm{g} / \mathrm{mL})$ of various internal standards such as aspirin, furosemide, lisinopril dihydrate, ambroxol hydrochloride, raloxifen and methocarbamol were experimentally studied. The most appropriate internal standard was raloxifen producing highest resolution and excellent separation of the peaks of the studied drugs.

Validation parameters: Method validation was performed according to ICH guidelines [28] to evaluate the suitability of the method for the separation and quantitation of RIV and CLP in pharmaceutical preparation and biological fluids.
Linearity and range: We obtained a linear relationship by plotting the peak area ratio [drug/I.S.] versus the drug concentration in $\mu \mathrm{g} / \mathrm{mL}$ using the discussed experimental conditions. $0.3-9.0 \mu \mathrm{g} / \mathrm{mL}$ for RIV and $0.5-25.0 \mu \mathrm{g} / \mathrm{mL}$ for CLP were the concentration ranges over which linearity was stated. The following equations were obtained from Linear regression analysis of the data:

\section{$\mathrm{P}=0.034+0.138 \mathrm{C}(\mathrm{r}=0.9999)$ for $\mathrm{RIV}$ \\ $\mathrm{P}=0.106+0.094 \mathrm{C}(\mathrm{r}=0.9999)$ for CLP}

Illustration: $\mathrm{P}$ refers to the peak area ratio, $\mathrm{C}$ refers to the concentration of the drug in $\mu \mathrm{g} / \mathrm{mL}$ and correlation coefficient is $\mathrm{r}$.

Correlation coefficients with high values and small values of intercepts prove that calibration curves were of high linearity.

From data statistical analysis [29] we found that the correlation coefficients $(r)$ were of high values indicating high linearity of the proposed method. Low scattering of the points around the calibration curves was predicted from the small values of the standard deviation of residuals $\left(\mathrm{S}_{\mathrm{y} / \mathrm{x}}\right)$, of intercept $\left(\mathrm{S}_{\mathrm{a}}\right)$, and of slope $\left(\mathrm{S}_{\mathrm{b}}\right)$. Owing to the small values of percentage relative standard deviation (RSD \%) and percentage relative errors (\% Er), the proposed method showed high accuracy and high precision as shown in Table 2.

\begin{tabular}{|l|l|l|}
\hline Parameter & RIV & CLP \\
\hline Method range $(\mu \mathrm{g} / \mathrm{mL})$ & $0.3-9.0$ & $0.5-25.0$ \\
\hline Intercept $(\mathrm{a})$ & 0.034 & 0.106 \\
\hline Slope $(\mathrm{b})$ & 0.138 & 0.094 \\
\hline Correlation coefficient $(\mathrm{r})$ & 0.9999 & 0.9999 \\
\hline S.D. of residuals $\left(\mathrm{S}_{\mathrm{y} / \mathrm{x}}\right)$ & $2.7 \times 10^{-3}$ & $6.7 \times 10^{-3}$ \\
\hline S.D. of intercept $\left(\mathrm{S}_{\mathrm{a}}\right)$ & $2.2 \times 10^{-3}$ & $4.6 \times 10^{-3}$ \\
\hline S.D. of slope $\left(\mathrm{S}_{\mathrm{b}}\right)$ & $4.0 \times 10^{-4}$ & $3.0 \times 10^{-4}$ \\
\hline Percentage relative standard deviation, $\% \mathrm{RSD}$ & 0.47 & 0.84 \\
\hline Percentage relative error, $\% \mathrm{error}$ & 0.21 & 0.38 \\
\hline Limit of detection, $\mathrm{LOD}(\mu \mathrm{g} / \mathrm{mL})$ & 0.05 & 0.16 \\
\hline Limit of quantitation, $\mathrm{LOQ}(\mu \mathrm{g} / \mathrm{mL})$ & 0.15 & 0.50 \\
\hline
\end{tabular}

Table 2: Data table for the determination of the RIV and CLP analytical performance by our proposed Micellar HPLC method.

Quantitation and detection limits: Quantitation limit (LOQ) was defined as the lowest concentration which can be measured according to ICH Q2R1 recommendations [28] below which the calibration curve linearity was lost. Detection limit (LOD) was defined as the minimum level at which the dug can be reliably detected (29). LOD and LOQ were determined using the following equation.

$$
\mathrm{LOQ}=10 \mathrm{~S}_{\mathrm{a} / \mathrm{b}} \mathrm{LOD}=3.3 \mathrm{~S}_{\mathrm{a} / \mathrm{b}}
$$

Illustration: $S_{a}$ is the intercept standard deviation of the calibration curve

Where $b$ is the calibration curve slope.

Table 2 illustrates that 0.15 and $0.50 \mu \mathrm{g} / \mathrm{mL}$ were LOQ values while 0.05 and $0.16 \mu \mathrm{g} / \mathrm{mL}$ were LOD values for RIV and CLP, respectively.
Method accuracy: The analysis results of the studied drugs were compared with the results obtained using the comparison method [17] for proving the accuracy of our proposed method. The obtained results were analyzed statistically using Student's t-test and variance ratio Ftest [29] which showed no significant difference between both methods performance regarding accuracy and precision, respectively. Student's t-test and variance ratio F-test are presented in Table 3.

\begin{tabular}{|c|c|c|c|c|}
\hline \multirow{3}{*}{$\begin{array}{l}\text { Analyt } \\
\text { e }\end{array}$} & \multicolumn{3}{|c|}{ Proposed technique } & $\begin{array}{l}\text { Reference method } \\
{[17]}\end{array}$ \\
\hline & $\begin{array}{l}\text { Amount } \\
\text { taken }\end{array}$ & $\begin{array}{l}\text { Amount } \\
\text { found }\end{array}$ & \multirow[t]{2}{*}{$\%$ Found } & \multirow[t]{2}{*}{$\%$ Found } \\
\hline & (mg/mL) & (mg/mL) & & \\
\hline
\end{tabular}


Citation: Heba Abd El-Aziz, Ibrahim F, Sharaf El-Din M and Fathy ME (2016) Micellar High Performance Liquid Chromatographic Determination of a Binary Mixture of Rivaroxaban and Clopidogrel and Application to Biological Fluids. Pharm Anal Acta 7: 506. doi: $10.4172 / 2153-2435.1000506$

Page 6 of 11

\begin{tabular}{|l|l|l|l|l|}
\hline & 0.3 & 0.298 & 99.6 & 98.77 \\
\hline & 2 & 2.013 & 100.69 & 100.44 \\
\hline RIV & 5 & 4.98 & 99.61 & 99.9 \\
\hline & 8 & 7.983 & 99.79 & \\
\hline & 9 & 9.018 & 100.2 & \\
\hline $\mathrm{X} \pm$ SD & & & $99.98 \pm 0.47$ & $99.70 \pm 0.85$ \\
\hline t-test & & & $0.60(2.45)$ & \\
\hline F-test & & & $3.34(6.94)$ & \\
\hline & 0.5 & 0.501 & 100.22 & 98.48 \\
\hline & 2.5 & 2.541 & 101.67 & 100.55 \\
\hline CLP & 10 & 10.009 & 100.1 & 99.88 \\
\hline & 15 & 14.902 & 99.35 & \\
\hline & 25 & 25.063 & 100.25 & \\
\hline $\mathrm{X} \pm$ SD & & & 100.32 & $99.64 \pm 1.06$ \\
\hline t-test & & & $1.01(2.45)$ & \\
\hline & & & & \\
\hline
\end{tabular}

\begin{tabular}{|l|l|l|l|l|}
\hline F-test & & $1.57(6.94)$ & \\
\hline
\end{tabular}

Table 3: Results of RIV and CLP assay in their pure form. The figures between parentheses are the tabulated $t$ and $F$ values at $\mathrm{P}=0.05$ [29]. N.B. Each result is the average of three separate determinations.

The reference method carried the assay of RIV and CLP in synthetic mixture using a reversed phase HPLC with acetonitrile: water (90:10, v/v)as a mobile phase and Kromasil C18 column $(250 \times 4.6 \mathrm{~mm}, 5 \mu)$ and UV detection at $240 \mathrm{~nm}$, the range of concentration obtained [1-20] for both drugs [17]. The advantages of the proposed assay over the comparison one [17] in that our proposed assay was applied for the analysis of RIV in human plasma and analysis of RIV and CLP in human urine. In addition, due to the small amount of organic solvent used in micellar mobile phase, low toxicity was predicted in micellar assay. Also, micellar assay save time as extraction process for human plasma and urine was cancelled.

Precision: Analyzing three concentrations on three replicates of each concentration in one day was defined as intra-day precision, but analyzing three concentrations on three replicates of each concentration over three successive days was inter-day precision. Very small values of the relative standard deviations proved that the proposed assay was of a reasonable repeatability and intermediate precision (Table 4).

\begin{tabular}{|c|c|c|c|c|c|c|c|}
\hline \multirow[t]{3}{*}{ Parameters } & & RIV concentration & & & CLP concentration & & \\
\hline & & $(\mathrm{mg} / \mathrm{mL})$ & & & $(\mathrm{mg} / \mathrm{mL})$ & & \\
\hline & & 0.5 & 2 & 5 & 2.5 & 10 & 25 \\
\hline \multirow[t]{7}{*}{ Intraday } & $\%$ Found & 100.18 & 98.26 & 99.75 & 99.41 & 99.45 & 99.55 \\
\hline & & 98.92 & 100.93 & 101.03 & 100.33 & 99.65 & 99.7 \\
\hline & & 98.55 & 98.33 & 99.2 & 101.52 & 100.23 & 100.06 \\
\hline & $(x)$ & 99.22 & 99.17 & 99.99 & 100.42 & 99.78 & 99.77 \\
\hline & $\pm \mathrm{SD}$ & 0.86 & 1.52 & 0.94 & 1.06 & 0.41 & 0.26 \\
\hline & $\%$ RSD & 0.86 & 1.54 & 0.94 & 1.05 & 0.41 & 0.26 \\
\hline & $\%$ Error & 0.5 & 0.89 & 0.54 & 0.61 & 0.23 & 0.15 \\
\hline \multirow[t]{7}{*}{ Interday } & & 99.23 & 99.69 & 100.02 & 99.68 & 100.38 & 98.96 \\
\hline & $\%$ Found & 98.82 & 99.03 & 99.62 & 100.24 & 99.67 & 99.42 \\
\hline & & 98.36 & 99.2 & 99.91 & 99.52 & 101.54 & 100.03 \\
\hline & $(x)$ & 98.8 & 99.31 & 99.85 & 99.81 & 100.53 & 99.47 \\
\hline & $\pm \mathrm{SD}$ & 0.44 & 0.34 & 0.21 & 0.38 & 0.94 & 0.54 \\
\hline & $\%$ RSD & 0.44 & 0.35 & 0.21 & 0.38 & 0.94 & 0.54 \\
\hline & $\%$ Error & 0.25 & 0.2 & 0.12 & 0.22 & 0.54 & 0.31 \\
\hline
\end{tabular}

Table 4: Precision data for the determination of RIV and CLP by the proposed Micellar HPLC method.

Method Robustness: Robustness was defined as the constancy of the peak area ratio with minor changes in the experimental parameters. Such parameters included percentage of n-propanol $(8.0 \pm 0.5 \%(\mathrm{v} / \mathrm{v}))$, SDS concentration $(0.185 \mathrm{M} \pm 0.002)$ and the mobile phase $\mathrm{pH}(4.0 \pm$
0.1 ). Table 5 illustrated that the peak area ratios of both drugs are not greatly affected by these minor changes.

\begin{tabular}{|c|c|c|c|c|}
\hline Item & $\begin{array}{c}\text { Amount } \\
\text { found }\end{array}$ & & \% Found & \\
\hline
\end{tabular}


Citation: Heba Abd El-Aziz, Ibrahim F, Sharaf El-Din M and Fathy ME (2016) Micellar High Performance Liquid Chromatographic Determination of a Binary Mixture of Rivaroxaban and Clopidogrel and Application to Biological Fluids. Pharm Anal Acta 7: 506. doi: $10.4172 / 2153-2435.1000506$

Page 7 of 11

\begin{tabular}{|c|c|c|c|c|}
\hline & $(\mathrm{mg} / \mathrm{mL})$ & & & \\
\hline & RIV & CLP & RIV & CLP \\
\hline \multicolumn{5}{|l|}{$\mathrm{pH}$} \\
\hline 3.9 & 4.98 & 15.142 & 99.6 & 100.94 \\
\hline 4 & 4.982 & 15.11 & 99.64 & 100.73 \\
\hline 4.1 & 5.012 & 14.915 & 100.24 & 99.43 \\
\hline$(x)$ & & & 99.83 & 100.37 \\
\hline \pm S.D. & & & 0.36 & 0.82 \\
\hline$\%$ RSD & & & 0.36 & 0.82 \\
\hline$\%$ Error & & & 0.21 & 0.47 \\
\hline \multicolumn{5}{|c|}{$\%(v / v)$ of $n$-Propanol } \\
\hline 7.5 & 4.938 & 14.925 & 98.76 & 99.5 \\
\hline 8 & 5.012 & 15.063 & 100.24 & 100.42 \\
\hline 8.5 & 5.053 & 15.121 & 101.06 & 100.8 \\
\hline$(x)$ & & & 100.02 & 100.24 \\
\hline \pm S.D. & & & 1.17 & 0.67 \\
\hline$\%$ RSD & & & 1.17 & 0.67 \\
\hline$\%$ Error & & & 0.67 & 0.39 \\
\hline \multicolumn{5}{|c|}{ SDS concentration, $\mathrm{M}$} \\
\hline 0.183 & 4.975 & 15.025 & 99.5 & 100.16 \\
\hline 0.185 & 5.017 & 14.757 & 100.34 & 98.38 \\
\hline
\end{tabular}

\begin{tabular}{|c|c|c|c|c|}
\hline 0.187 & 5.076 & 14.907 & 101.52 & 99.38 \\
\hline$(\times x)$ & & & 100.45 & 99.31 \\
\hline \pm S.D. & & & 1.02 & 0.89 \\
\hline$\%$ RSD & & & 1.01 & 0.9 \\
\hline \% Error & & & 0.58 & 0.52 \\
\hline
\end{tabular}

Table 5: Robustness study of the proposed method using rivaroxaban $(5.0 \mu / \mathrm{mL})$ and clopidogrel $(15.0 \mu / \mathrm{mL})$.

Method selectivity: Common tablet excipients may interfere with the assay of the drugs which affect the selectivity of the method. In our assay these compounds did not interfere with the results of the proposed method referring to high selectivity of the method. Also, no interference resulted from human plasma and urine matrices although extraction process was cancelled as micelles dissolve proteins.

\section{Method applications}

RIV/CLP binary mixtures analysis: Figure 2 showed the simultaneous analysis of RIV and CLP in laboratory prepared binary mixtures keeping their recommended pharmaceutical ratio, 1:5 as an application of the proposed method. In the laboratory prepared mixtures, the concentrations taken of both drugs were presented in the linearity range. When we compared the results obtained by the proposed method with those obtained using the reference one [17], good agreement were found. High percentages found and the small values of the relative standard deviations and percentage relative errors proved that the proposed method was of high accuracy and precision. Table 6 shows the results obtained for the binary prepared mixtures (Figure 3) (Table 7).

\begin{tabular}{|c|c|c|c|c|c|c|c|c|}
\hline RIV/CLP ratio & & & & & $\%$ Found & & Reference & \\
\hline & Amount taken & & Amount found & & & & Method(17) & \\
\hline & $(\mathrm{mg} / \mathrm{mL})$ & & $(\mathrm{mg} / \mathrm{mL})$ & & & & & \\
\hline & RIV & CLP & RIV & CLP & RIV & CLP & RIV & CLP \\
\hline \multirow[t]{4}{*}{ 1:05 } & 0.5 & 2.5 & 0.491 & 2.54 & 98.3 & 101.52 & 98.77 & 98.48 \\
\hline & 2 & 10 & 2.013 & 9.94 & 100.64 & 99.41 & 100.44 & 100.55 \\
\hline & 5 & 25 & 4.995 & 25.02 & 99.91 & 100.06 & 99.9 & 99.88 \\
\hline & & & & & 99.62 & 100.33 & 99.7 & 99.64 \\
\hline \multicolumn{9}{|l|}{$\square \xi$} \\
\hline$\pm \mathrm{SD}$ & & & & & \pm 1.20 & \pm 1.08 & \pm 0.85 & \pm 1.06 \\
\hline$\%$ RSD & & & & & 1.2 & 1.07 & 0.85 & 1.06 \\
\hline$\%$ Error & & & & & 0.69 & 0.62 & 0.49 & 0.61 \\
\hline$t$ & & & & & 0.1 & 0.79 & & \\
\hline $\mathrm{F}$ & & & & & 1.97 & 1.05 & & \\
\hline
\end{tabular}

Table 6: Results for RIV and CLP drugs determination in synthetic mixtures in ratios of 1:5 (w/w) by the proposed micellar method. N. B. Each result is the average of three separate determinations. The values of tabulated $t$ and $F$ tests are 2.78 and 19.00 , respectively at $\mathrm{p}=0.05$ (29). 
Citation: Heba Abd El-Aziz, Ibrahim F, Sharaf El-Din M and Fathy ME (2016) Micellar High Performance Liquid Chromatographic Determination of a Binary Mixture of Rivaroxaban and Clopidogrel and Application to Biological Fluids. Pharm Anal Acta 7: 506. doi: $10.4172 / 2153-2435.1000506$

Page 8 of 11

\begin{tabular}{|c|c|c|c|c|c|c|c|c|}
\hline Formulation & & & & & $\%$ Found & & Reference & \\
\hline & Amount taken & & Amount found & & & & Method(17) & \\
\hline & $(\mathrm{mg} / \mathrm{mL})$ & & $(\mathrm{mg} / \mathrm{mL})$ & & & & & \\
\hline & RIV & CLP & RIV & CLP & RIV & CLP & RIV & CLP \\
\hline Laboratory prepared tablet & 0.5 & 2.5 & 0.507 & 2.52 & 101.42 & 101.04 & 99.37 & 100.47 \\
\hline \multirow[t]{3}{*}{ (RIV 15 mg+CLP 75 mg ) } & 2 & 10 & 1.99 & 9.97 & 99.46 & 99.69 & 100.47 & 99.65 \\
\hline & 5 & 25 & 5.01 & 25.03 & 100.07 & 100.1 & 99.92 & 100.06 \\
\hline & & & & & 100.32 & 100.28 & 99.92 & 100.06 \\
\hline$\pm \mathrm{SD}$ & & & & & \pm 1.00 & \pm 0.69 & \pm 0.55 & \pm 0.41 \\
\hline$\%$ RSD & & & & & 1 & 0.69 & 0.55 & 0.41 \\
\hline$\%$ Error & & & & & 0.58 & 0.4 & 0.32 & 0.24 \\
\hline $\mathrm{t}$ & & & & & 0.6 & 0.47 & & \\
\hline $\mathrm{F}$ & & & & & 3.32 & 2.85 & & \\
\hline
\end{tabular}

Table 7: Assay results for the determination of the RIV and CLP in their laboratory prepared tablet by the proposed HPLC method. N.B. Each result is the average of three separate determinations. The values of tabulated $\mathrm{t}$ and $\mathrm{F}$ tests are 2.78 and 19.00 respectively at $\mathrm{p}=0.05$ [29].

Tablet analysis: Our proposed method was applied for the analysis of both studied drugs in their prepared tablet. Table 8 shows that the results obtained are in good agreement with the results of the comparison one [17]. The obtained data were statistically analyzed using Student's t-test and variance ratio F-test [29] showing no significant difference between the behavior of the two methods (Table 8 ), so our method is of high accuracy and precision. Chromatogram of good resolved sharp peaks of RIV and CLP in their prepared tablet was shown in Figure 4.

\begin{tabular}{|c|c|c|c|}
\hline Parameter & Amount taken & Amount found & \% Found \\
\hline & $(\mathrm{mg} / \mathrm{mL})$ & $(\mathrm{mg} / \mathrm{mL})$ & \\
\hline & 0.3 & 0.299 & 99.9 \\
\hline & 0.45 & 0.45 & 100.2 \\
\hline$\square \xi$ & 0.6 & 0.599 & 99.92 \\
\hline \pm SD & & & 100.01 \\
\hline$\%$ RSD & & & \pm 0.17 \\
\hline$\%$ Error & & & 0.17 \\
\hline
\end{tabular}

Table 8: Assay results for the determination of rivaroxaban in spiked human plasma using the proposed method.

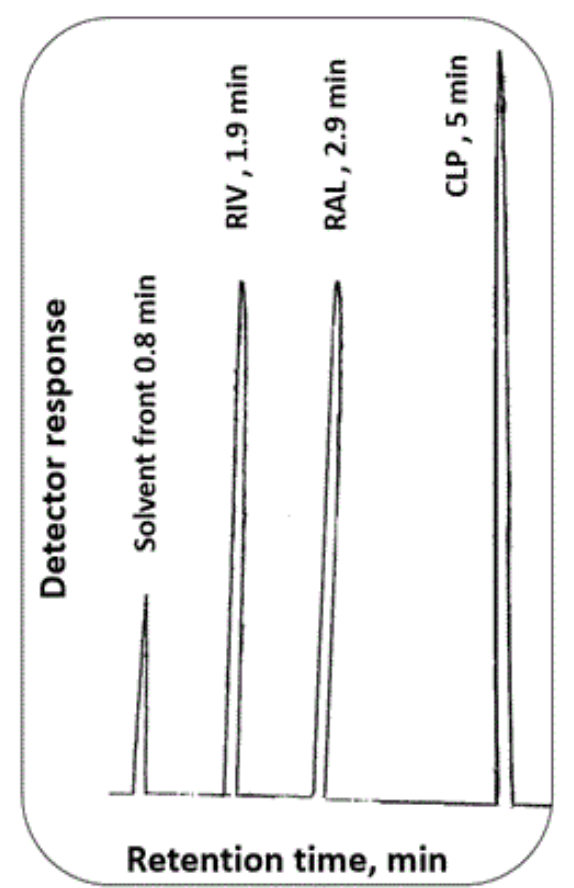

Figure 4: chromatogram of co-formulated prepared tablet of 5.0 $\mu \mathrm{g} / \mathrm{mL}$ RIV and $25.0 \mu \mathrm{g} / \mathrm{mL}$ CLP using $5.0 \mu \mathrm{g} / \mathrm{mL}$ RAL (I.S) in a mobile phase consisting of 0.185 M SDS, $0.3 \%$ triethylamine, $8 \% \mathrm{n}$ propanol adjusted at $\mathrm{pH} 4.0$ using $0.02 \mathrm{M}$ orthophosphoric acid.

Application to biological fluid: Rivaroxaban is rapidly absorbed with maximum concentrations appearing 2-4 h after tablet administration. The absolute bioavailability of rivaroxaban is high (80-100 \%). Plasma 
Citation: Heba Abd El-Aziz, Ibrahim F, Sharaf El-Din M and Fathy ME (2016) Micellar High Performance Liquid Chromatographic Determination of a Binary Mixture of Rivaroxaban and Clopidogrel and Application to Biological Fluids. Pharm Anal Acta 7: 506. doi: $10.4172 / 2153-2435.1000506$

Page 9 of 11

concentrations peak reached at 2.5-4 h after oral administration. RIV concentration in plasma was from 20 to $660 \mathrm{ng} / \mathrm{mL}$ after $2 \mathrm{~h}$ of oral administration of $15 \mathrm{mg}$ RIV [30]. RIV analysis in spiked human plasma revealed the high sensitivity of the proposed procedure.

Clopidogrel is rapidly, but incompletely (about 50\%), absorbed after oral administration and is highly metabolized in the liver to produce two metabolites; the main circulating metabolite $(85 \%)$ being the inactive carboxylic acid derivative. Clopidogrel is oxidized to 2-oxoclopidogrel with further hydrolysis to produce the active thiol derivative, which has not been identified in plasma. Clopidogrel and its metabolites are equally excreted in urine.

Peak plasma concentration for clopidogrel is $0.00025 \mathrm{mg} / \mathrm{L}$ (which is lower than the concentration range of the proposed method) and peak concentration of the inactive metabolite within $0.8-1 \mathrm{~h}$. was between 0.8 and $0.11 \mathrm{mg} / \mathrm{L}$. Clopidogrel and its inactive metabolite bind plasma proteins $98 \%$ and $94 \%$, respectively [1]. Therefore, we did not determine CLP in human plasma using our proposed method.

RIV analysis in spiked human plasma: Figures $5 \mathrm{a}$ and $\mathrm{b}$ show RIV peak in spiked human plasma. The results obtained were displayed in Table 9. By plotting the peak area of RIV against the drug concentration in $\mu \mathrm{g} / \mathrm{mL}$, we found that the relationship was of high linearity. The following equation illustrates data regression analysis linearity:

$$
\mathrm{P}=0.031+0.039 \mathrm{C}(\mathrm{r}=0.9999)
$$

Illustration: $\mathrm{P}$ refers to the peak area ratio, $\mathrm{C}$ refers to concentration of the drug in $\mu \mathrm{g} / \mathrm{mL}$ and $\mathrm{r}$ is the correlation coefficient.

The high value of the correlation coefficient $(r)$ value indicating that human plasma calibration curve of high linearity.

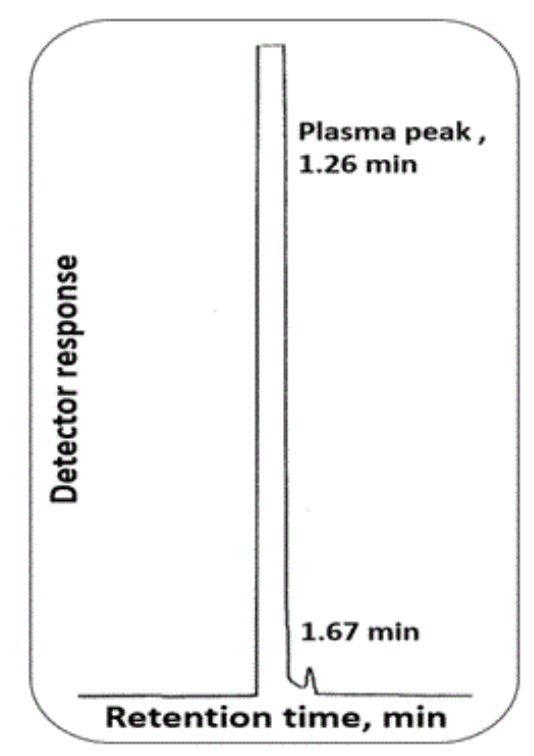

Figure 5a: Chromatogram of blank plasma in $0.185 \mathrm{M}$ SDS, $0.3 \%$ triethylamine, $8 \% \mathrm{n}$-propanol as a mobile phase it's $\mathrm{pH}$ adjusted at 4.0 with $0.02 \mathrm{M}$ orthophosphoric acid.

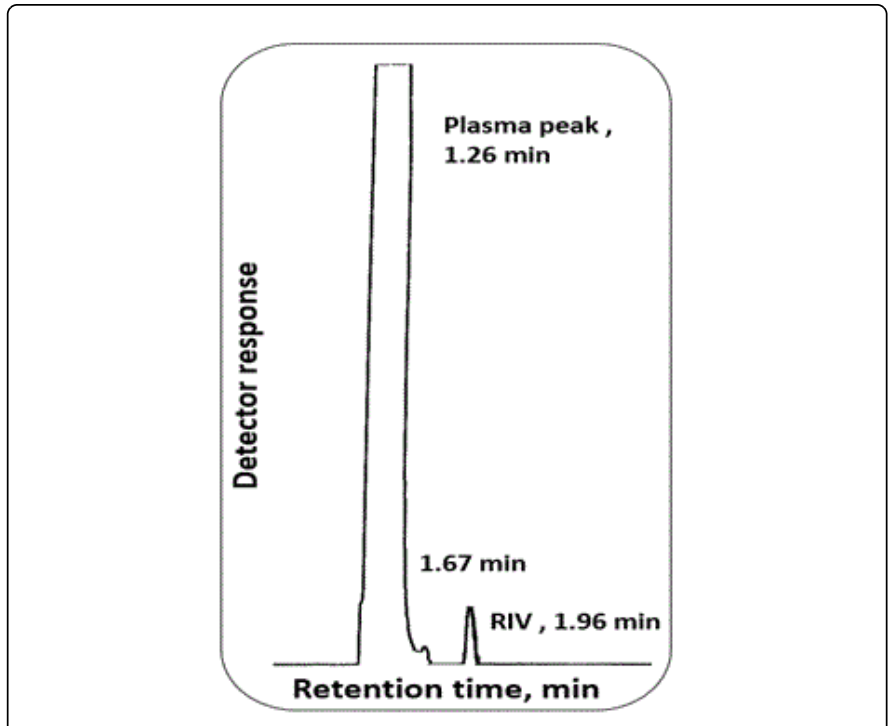

Figure 5b: Chromatogram of human plasma spiked with RIV (0.5 $\mu \mathrm{g} / \mathrm{mL})$ in $(0.185 \mathrm{M}$ SDS, $0.3 \%$ triethylamine, $8 \% \mathrm{n}$-propanol at $\mathrm{pH}$ 4.0 using $0.02 \mathrm{M}$ orthophosphoric acid).

Analysis of spiked human urine: Approximately $66 \%$ of the dose of rivaroxaban is excreted via the kidneys unchanged, so it could be determined in urine. Also Clopidogrel and its metabolites are equally excreted in urine. So, both drugs are spiked in human urine and analysed. Typical chromatogram of RIV and CLP in spiked human urine was shown in Figures $6 a$ and b. Spiked urine results were presented in Table 9.

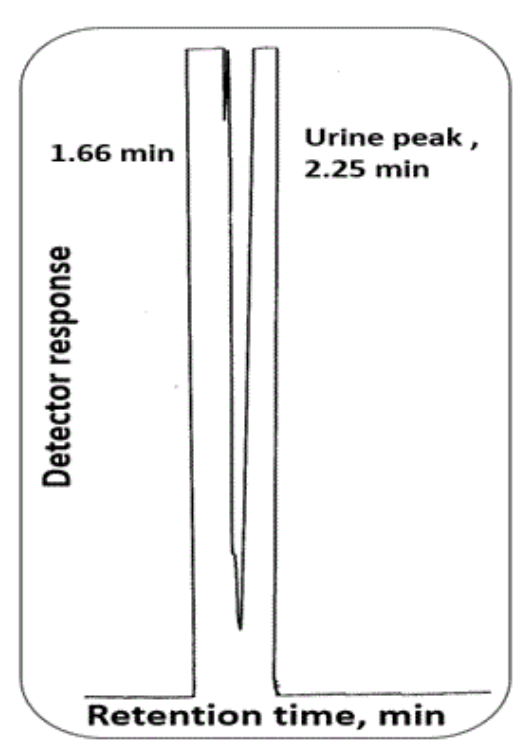

Figure 6a: Blank urine using 0.185 M SDS, 0.3\% triethylamine, $8 \%$ $\mathrm{n}$-propanol prepared at $\mathrm{pH} 4.0$ with $0.02 \mathrm{M}$ orthophosphoric acid. 
Citation: Heba Abd El-Aziz, Ibrahim F, Sharaf El-Din M and Fathy ME (2016) Micellar High Performance Liquid Chromatographic Determination of a Binary Mixture of Rivaroxaban and Clopidogrel and Application to Biological Fluids. Pharm Anal Acta 7: 506. doi: $10.4172 / 2153-2435.1000506$

Page 10 of 11

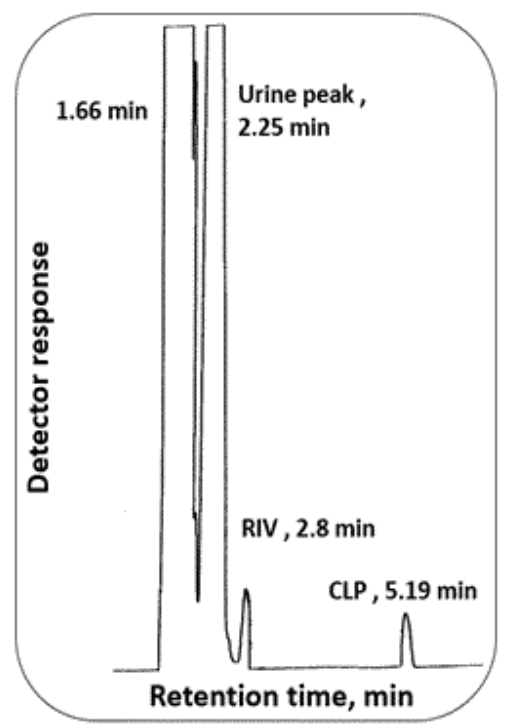

Figure 6b: Chromatogram for the determination of RIV (0.9 $\mu \mathrm{g} / \mathrm{mL})$ and CLP $(2.0 \mu \mathrm{g} / \mathrm{mL})$ Spiked in human urine using $0.185 \mathrm{M}$ SDS, $0.3 \%$ triethylamine, $8 \% \mathrm{n}$-propanol at $\mathrm{pH} 4.0$ adjusted using $0.02 \mathrm{M}$ orthophosphoric acid.

\begin{tabular}{|c|c|c|c|}
\hline Compound & $\begin{array}{c}\text { Proposed } \\
\text { method }\end{array}$ & & \\
\hline & $\begin{array}{c}\text { Amount } \\
\text { taken }\end{array}$ & Amount found & $\%$ Found \\
\hline & $(\mathrm{mg} / \mathrm{mL})$ & $(\mathrm{mg} / \mathrm{mL})$ & \\
\hline \multirow[t]{4}{*}{ RIV } & 0.6 & 0.598 & 99.68 \\
\hline & 0.9 & 0.903 & 100.33 \\
\hline & 1.2 & 1.198 & 99.91 \\
\hline & 1.5 & 1.499 & 99.95 \\
\hline Mean \pm S.D. & & & $99.97 \pm 0.27$ \\
\hline$\%$ RSD & & & 0.26 \\
\hline$\%$ Error & & & 0.14 \\
\hline \multirow[t]{5}{*}{ CLP } & 0.6 & 0.602 & 100.42 \\
\hline & 1 & 0.997 & 99.71 \\
\hline & 1.4 & 1.401 & 100.09 \\
\hline & 2 & 1.998 & 99.91 \\
\hline & 2.4 & 2.402 & 100.1 \\
\hline Mean \pm S.D. & & & $100.05 \pm 0.26$ \\
\hline$\%$ RSD & & & 0.26 \\
\hline$\%$ Error & & & 0.12 \\
\hline
\end{tabular}

Table 9: Rivaroxaban and Clopidogrel assay in spiked human urine using the proposed micellar HPLC method.

\section{Conclusion}

A sensitive, accurate and rapid micellar liquid chromatographic technique was developed for determination of RIV and CLP binary mixtures with detection limits of $0.05,0.16 \mu \mathrm{g} / \mathrm{mL}$ and quantitation limits of $0.15,0.49 \mu \mathrm{g} / \mathrm{mL}$ for RIV and CLP, respectively. Also, prepared tablets could be analyzed using the developed method. The developed and validated micellar method could be applied in quality control laboratories. The developed method was extended for the determination of both drugs in biological fluids due to its high sensitivity. RIV was determined in spiked human plasma and both drugs were determined in spiked human urine with satisfactory results without prior extraction processes.

\section{References}

1. Moffat AC, Osselton MD, Widdop B (2004) Clarkes Analysis of Drugs \& Poisons (3rd edn.) Pharmaceutical Press, London, 1371: 1641.

2. Sweetman SC (2009) Martindale: The Complete Drug Reference (36th edn) The Pharmaceutical Press, London.

3. (2007) The United States Pharmacopoeia 34, The National Formulary 25, US Pharmacopeial Convention Rockville, MD.

4. Çelebier M, Reçber T, Koçak E, Altınoz S, Kır S (2015) Determination of Rivaroxaban in Human Plasma by Solid-Phase Extraction-High Performance Liquid Chromatography. J chromatogr sci.

5. Prabhune SS, Dighe V, Pradhan NS (2015) Enantiomeric Separation of Rivaroxaban by a chiral liquid Chromatographic method. Int J of Pharm Sci, 7: 399-402.

6. Seshamamba PSV, Veera PV, Sekaran CB (2014) Application of Stability Indicating HPLC Method with UV Detector to the Analysis of Rivaroxaban in Bulk and Tablet Dosage Form. Chem Sci Trans 3: 1546-1554.

7. Kasad PA, Muralikrishna KS (2013) Design and Validation of Dissolution Profile of Rivaroxaban by Using RP-HPLC Method in Dosage Form. Asian J Pharm Ana 3: 75-78.

8. Çelebier M, Reçber T, Koçak E, Altınoz S (2013) RP-HPLC method development and validation for estimation of Rivaroxaban in pharmaceutical dosage forms. Braz J Pharm Sci 49: 359-366.

9. Sekhar KC, Vani PS, Lakshmi AD, ChL Devi, Barik A. et al. (2012) A New method Development and validation for analysis of Rivaroxaban in formulation by RP-HPLC. Research Desk 1: 24-33.

10. Kasad PA (2013) Photolytic-Thermal Degradation Study and Method Development of Rivaroxaban by RP-HPLC. Int J Pharm Tech Res 5: 1254-1263.

11. Kasad PA, Muralikrishna KS (2013) Method Development and Acid Degradation Study of Rivaroxaban by RP-HPLC in bulk. Asian J Pharm Ana 3: 62-65.

12. Kasad PA, Muralikrishna KS (2013) Base Degradation Study and Method Development of Rivaroxaban by RP-HPLC in Bulk. Asian J Pharm Ana 3: 98-101.

13. Abdallah MA, Al-Ghobashy MA, Lotfy HM (2015) Investigation of the profile and kinetics of degradation of rivaroxaban using HPLC, TLC densitometry and LC/MS/MS: Application to pre-formulation studies. Elsevier B.V, Cairo University 53: 53-61.

14. Lories IB, Mostafa AA, Girges MA (2013) High Performance Liquid Chromatography, TLC Densitometry, First derivative and First-derivative ratio spectrophotometry for determination of Rivaroxaban and its alkaline Degradates in Bulk Powder and its Tablets. J Chromatograph Separat Techniq 4: 4-9.

15. Rohde G (2008) Determination of Rivaroxaban-a novel, oral, direct Factor Xa inhibitor--in human plasma by high-performance liquid chromatography-tandem mass spectrometry. J Chromatogr B Analyt Technol 1: 43-50.

16. Korosteleva M, Bihana K, Ferreola L, Tissota N, Hulota JS, et al. (2014) Simultaneous determination of Rivaroxaban and dabigatran levels in 
Citation: Heba Abd El-Aziz, Ibrahim F, Sharaf El-Din M and Fathy ME (2016) Micellar High Performance Liquid Chromatographic Determination of a Binary Mixture of Rivaroxaban and Clopidogrel and Application to Biological Fluids. Pharm Anal Acta 7: 506. doi: $10.4172 / 2153-2435.1000506$

Page 11 of 11

human plasma by high-performance liquid chromatography-tandem mass spectrometry. J Pharm Biomed Anal 100: 230-235.

17. Prajapati AM, Pate HA (2015) Simulatneous RP-HPLC Method Development \& Validation of Clopidogrel \& Rivaroxaban in Synthetic Mixture. Int J Pharm 5: 610-613.

18. Krishna VS, Kumar DR, Balamuralikrishna K, Rambabu C (2014) Development \& Validation of stability indicating RP-HPLC Method for the determination of clopidogrel bisulphate in bulk and its dosage forms. Scholars Research Library 6: 366-374.

19. Alarfaj NA (2012) Stability-indicating liquid chromatography for determination of Clopidogrel bisulfate in tablets: Application to content uniformity testing. J Saudi Chem Soc 16: 23-30.

20. AlKhayat MA, Haidar S, Mando H (2012) Development \& Validation of RPHPLC Method for Determination of Clopidogrel in Tablets. Int J Pharm Sci Rev Res 14: 1-5.

21. Ghiasia G, Farshchia A, Bahramia Gh (2009) High Performance Liquid Chromatographic Determination of Inactive Carboxylic Acid Metabolite of Clopidogrel in Human Serum: Application to a Bioequivalence Study. J Chromatogr B Analyt Technol Biomed Life Sci 5: 231-238.

22. Issa MM, Nejem RM, Abu-Shanab A, Ioana R, Staden SV (2013) Resolution of Ternary Mixture of Aspirin, Atorvastatin, \& Clopidogrel by Chemometric Assisted UV-Spectroscopic \& Liquid Chromatography Methods. Int J of Spectroscopy 1-8.

23. Devkare PN, Jain HK (2013) Development \& Validation of RP-HPLC Method for Simulatneous Estimation of S(-) Amlodipine Besylate \&
Clopidogrel Bisulfate in Tablet Dosage Form. International Journal of Pharmacy and Pharmaceutical Sciences 5.

24. Pandya N, Mashru RC (2012) Simulatneous Estimation of Rosuvastatin Calcium \& Clopidogrel Bisulfate in Combined Pharmaceutical Formulation. Int J Drug Formul Res 3.

25. Nagavi JB, Gurupadayya B, Preethi G (2014) Validated Bio-Analytical Method Development for Simultaneous Estimation of Clopidogrel \& Asprin in Human Plasma by RP-Ultra Fast Liquid Chromatography. World J of Pharmcy \& Pharmaceutical Sciences 3: 518-531.

26. Syeda K, Ramya S, Snehalatha T, Kanakadurga M, Thimmareddy (2012) Development \& Validation of RP-HPLC Method for Simulatneous Estimation of Amlodipine Besylate \& Clopidogrel in Bulk \& Tablet Dosage Forms. Int J Phar Technol 4: 4337-4349.

27. Thomas DP, Foly JP (2008) Improved efficiency in micellar liquid chromatography using triethyl amine and 1-butanol as mobile phase additives to reduce surfactant adsorption. J Chromatography A 1205: 36-45.

28. (2007) International Conference on Harmonization (ICH) Guidelines.

29. Miller JN, Miller JC (2005) Statistics \& Chemometrics for Analytical Chemistry (5th Edn) Harlow, England: Pearson Education Limited 107-149.

30. Samama MM, Contact G, Spiro TE, Perzborn E, Guinet C, et al. (2012) Evaluation of the anti-factor Xa chromogenic assay for the measurement of Rivaroxaban plasma concentrations using calibrators and controls. Thromb Hemost 107: 379-387. 